\title{
Physical Activity Among Persons Aging with Mobility Disabilities: Shaping a Research Agenda
}

\author{
Dori E. Rosenberg,, ${ }^{1}$ Charles H. Bombardier, ${ }^{1}$ Jeanne M. Hoffman, ${ }^{2}$ and Basia Belza ${ }^{3,4,5}$ \\ ${ }^{1}$ Harborview Medical Center, Department of Rehabilitation Medicine, University of Washington, 325 Ninth Avenue, Seattle, \\ WA 98104, USA \\ ${ }^{2}$ Department of Rehabilitation Medicine, University of Washington, Seattle, WA 98195, USA \\ ${ }^{3}$ School of Nursing, University of Washington, Seattle, WA 98195, USA \\ ${ }^{4}$ School of Public Health, University of Washington, Seattle, WA 98195, USA \\ ${ }^{5}$ Coordinating Center, CDC Healthy Aging Research Network, University of Washington, Seattle, WA 98195, USA
}

Correspondence should be addressed to Dori E. Rosenberg, dorir@uw.edu

Received 15 December 2010; Accepted 17 April 2011

Academic Editor: Susan Hughes

Copyright ( 2011 Dori E. Rosenberg et al. This is an open access article distributed under the Creative Commons Attribution License, which permits unrestricted use, distribution, and reproduction in any medium, provided the original work is properly cited.

With the aging of the baby boomer population and their accompanying burden of disease, future disability rates are expected to increase. This paper summarizes the state of the evidence regarding physical activity and aging for individuals with mobility disability and proposes a healthy aging research agenda for this population. Using a previously published framework, we present evidence in order to compile research recommendations in four areas focusing on older adults with mobility disability: (1) prevalence of physical activity, (2) health benefits of physical activity, (3) correlates of physical activity participation, and, (4) promising physical activity intervention strategies. Overall, findings show a dearth of research examining physical activity health benefits, correlates (demographic, psychological, social, and built environment), and interventions among persons aging with mobility disability. Further research is warranted.

\section{Introduction}

Disability rates are expected to increase with the aging of the baby boomer population [1]. Indeed, recent National Health and Nutrition Examination Survey (NHANES) data suggest that for those 60-69 years old, the prevalence of disability in activities of daily living, instrumental activities of daily living, and mobility is increasing $[1,2]$. The future burden could overwhelm healthcare systems, rehabilitation medicine clinics, and public health agencies. With the increase in an aging demographic, researchers are focusing on ways to prevent secondary conditions in aging persons. Physical activity is recognized as a behavior with strong positive effects on mental, physical, and cognitive health [3]. The benefit of increased physical activity across all age groups is substantial. Thus, efforts to promote physical activity among older adults with existing mobility disability could help prevent a large burden of secondary illness.
Although much physical activity research has focused on older adults who are free of disability and illness, the need still exists for a healthy aging research agenda specific to older adults with mobility disability for tertiary prevention purposes. Promoting healthy aging among people who already have mobility disabilities has been neglected. People with mobility disabilities may benefit from living in accordance with a healthy aging model that includes "the development and maintenance of optimal physical, mental, and social well-being and function" [4]. While the underlying mobility disability may not be reversible, general mental, physical, and cognitive health can be improved.

Prohaska et al. [5] set forth a framework revolving around four questions to help shape the public health research agenda on physical activity and aging. The purpose of this paper is to employ this framework to organize a research agenda for promoting physical activity among persons aging with mobility disability. The four topic areas 
we describe in this paper, based on the framework of Prohaska et al. [5], are as follows:

(1) surveillance data on the prevalence of physical activity among older adults with mobility disability,

(2) overview of the health benefits of physical activity and the consequences of sedentary behavior in older adults with mobility disability,

(3) correlates and determinants of physical activity participation among older adults with mobility disability,

(4) promising intervention approaches for promoting physical activity in older populations with mobility disability.

While there are many categories of disability including mobility, sensory, intellectual, cognitive, or emotional disabilities $[6,7]$, in the current paper we focus on mobility disability. Mobility disability in this paper is defined by Patla and Shumway-Cook [8] as occurring "when impairments in mobility restrict the ability of individuals to move about in their natural environment in order to carry out activities essential to daily life."

The International Classification of Function (ICF) framework broadly defines health conditions that can lead to body functions and structure, activity, and participation alterations as "diseases, disorders, injuries, aging, and congenital anomaly" [9]. Therefore, while we use specific examples, we consider mobility disability to be caused by many different factors. Thus, individuals may be born with or develop mobility disability early in life and are aging with this condition. In addition, as people age, chronic diseases such as cardiovascular disease, diabetes, stroke, and arthritis can lead to mobility disability. Finally, mobility disability can be caused by a single, identifiable condition such as multiple sclerosis (MS) or a trauma which resulted in spinal cord injury (SCI) [8] but can also be compounded by development of other chronic diseases found in the general aging population [10].

Regardless of the etiology, there is a need to address physical activity promotion for those with any type of condition that leads to mobility disability. We include in this review both persons aging with specific disabling conditions, such as MS, and those with more general conditions (e.g., frailty or decreased ability to walk due to arthritis or diabetes) that result in mobility disabilities. Although we focus on persons with mobility disability, where data are lacking or when definitions are unclear, we will discuss research in the broader populations of persons with any type of disability.

\section{Methods}

To shape a research agenda on physical activity among persons aging with mobility disabilities, we conducted a scoping review. A scoping review was selected instead of a systematic review because the purpose of our investigation was to summarize research on a broad topic area and identify research gaps in an area that has not been reviewed before [11]. It was not deemed appropriate to limit our inclusion of studies nor to assess studies for quality as is required for a systematic review. To conduct our scoping review, we selected literature from the fields of public health and rehabilitation medicine which included evidence-based review articles, nationwide data systems, and landmark studies where reviews were lacking. Criteria for including studies were determined after review of the literature and was based on best fit to provide a broad background and to reflect the most current research on physical activity and mobility disability. Searches were conducted in PubMed using various key terms depending on the topic area. Key search terms for capturing populations with mobility disabilities included "mobility disability," "mobility limitation," and "mobility impairment" as well as terms for various chronic illnesses that can lead to mobility disability (e.g., stroke, multiple sclerosis, arthritis). We also used reference lists of review articles to find additional sources. Several well-known government reports were also included (e.g., Physical Activity Guidelines for Americans 2008, Institute of Medicine report on the Future of Disability in America).

\section{Findings}

3.1. Prevalence of Physical Activity among Populations Aging with Mobility Disabilities. Measuring the prevalence of physical activity among those with mobility disability presents several difficulties. Definitions and criteria for mobility disability are based on various indicators. People can selfidentify as having a mobility disability, they may have a diagnosable condition that causes mobility disability, or they may have specific activity limitations which are considered to be related to mobility disability $[12,13]$. There are little data available describing the prevalence of disability, particularly in the younger aging groups [14]. Recently published data suggest that "mobility difficulties," based on self-reports of ability to walk $1 / 4$ mile, walk up 10 steps, stand or sit for 2 hours, and standing, bending, or kneeling without using special equipment, increased among all age groups over the 8-year period between 1998 and 2006 [14]. Another study estimated the prevalence of "mobility impairment" among Medicare beneficiaries over 65 years old [15]. In the study, mobility impairment was based on responses to questions about walking ability and function including difficulty walking 2 or 3 blocks, obtaining help for walking from another person, or using assistive devices to walk. Difficulty was based on a hierarchy in which people were classified as having mild, moderate, or severe mobility limitations. Nonwalkers were classified separately. The total number of those with mobility impairments in 2001 was 14.1 million [15]. Out of these, 9.5 million had mild mobility impairment, and 1.2 million had severe mobility impairment. Overall, $28.3 \%$ of Medicare beneficiaries had moderate to severe functional impairments [16]. The causes of mobility disability are diverse and span a variety of health conditions. Mobility disability has been highest for those with musculoskeletal diseases followed by neurological disorders, heart diseases, lung diseases, diabetes, and cancer $[2,17]$. Additionally, mobility disability due to high body 
mass index (BMI), which stresses joints resulting in obesityrelated mobility disability, is on the rise with $42.2 \%$ of persons with obesity reporting functional impairment in the National Health and Nutrition Examination Surveys $[18,19]$.

Regarding the prevalence of physical activity in persons aging with mobility disability, little is known about their physical activity patterns, and no specific population based information exists on the percent of people with mobility disability who meet the physical activity guidelines. Instead, there are data sources describing rates of physical activity among the general population with any type of disability. The 2008 Physical Activity Guidelines recommend that persons with disabilities meet the same guidelines as for healthy adults or do as much as they are able and avoid being inactive [20]. Healthy People 2020 includes an objective to increase the number of older adults with physical or cognitive function limitations who engage in any intensity of leisure time physical activity [16]. Data from the National Health Interview Survey indicated that $33.7 \%$ of older adults with physical or cognitive function limitations engaged in light, moderate, or vigorous intensity activity [16]. The goal is to increase the proportion to $37.1 \%$. A different source of data, the Behavioral Risk Factor Surveillance System, demonstrated that fewer persons with disabilities meet physical activity guidelines $(37.7 \%$ among those with disabilities compared to $49.4 \%$ among those without disabilities in this dataset) [21]. Similarly, data from the Healthy People 2010 database showed higher rates of engaging in no leisure time physical activity for people with disabilities (54\%) compared to those without (32\%) in 2008 [22]. For those with coronary heart disease (CHD), rates of attending cardiac rehabilitation are low and drop after completion [23]. While data sources vary, it is clear that at a population level, persons with disabilities are less active than those without.

Another way of viewing discrepancies in physical activity levels between those with and without chronic conditions is through Tudor-Locke's review of expected pedometer steps/day for persons with chronic illnesses and disabilities [24]. The researchers found that the median steps/day values were as follows: 5,887 (waist mounted) and 6,006 (ankle worn) for persons with neuromuscular diseases, 4,086 (waist mounted) for persons with arthritis, 4,695 (ankle worn) for persons with post-stroke chronic hemiparesis, and 6,515 (ankle worn) for persons with intermittent claudication. The values for those with chronic conditions were lower than those for otherwise healthy adults who typically obtain between 7,000 and 13,000 steps/day [24]. Regardless of the data source and definition used, the discrepancy in physical activity levels between those with and without various types of mobility disability appears to be consistent and has also been shown among those with SCI [25], arthritis [26, 27], heart disease [23], and MS [28].

Understanding physical activity patterns in individuals with mobility disability is complicated by the frequent use of single time point estimates. For example, research has shown that during inpatient rehabilitation, duration of dynamic activities increases over time, but shortly after discharge this decreases. In one study of SCI inpatients, activity duration decreased by $33 \%$ postdischarge [29]. In addition, health problems, such as illness, progression of disease, pain, and fatigue, can cause fluctuations in physical activity patterns. Longitudinal studies of physical activity patterns are needed to better assess the potential nuances among those aging with mobility disability and to help build interventions that address such differences.

3.1.1. Measurement of Physical Activity. Another difficulty in tracking physical activity among persons with mobility disability, whether for surveillance or in research trials, is the lack of validated measures for assessing physical activity in persons with mobility disability. It is important to use measures that capture lower intensity activities, which may be more common among persons aging with mobility disability, that include the use of assistive devices to ambulate and that can be administered in a variety of formats (e.g., interviewer administered by phone) [30]. Several self-reported measures of physical activity have been developed for use among persons with disabilities, which could include those with mobility disabilities [30]. These include the Physical Activity and Disability Survey [31], Physical Activity Recall Assessment for People with Spinal Cord Injury [32], and Physical Activity Scale for Individuals with Physical Disabilities [33]. There are also measures that have been developed for use among older adults including the Community Healthy Activities Model Program for Seniors (CHAMPS) [34], Physical Activity Scale for the Elderly [35], and Yale Physical Activity Survey [36]. Measures that assess physical activity for aging persons with mobility disabilities are lacking. A review of each measure and its validity evidence is beyond the scope of this paper, but more research on these self-report measures, including which perform the best for people aging with mobility disability, is needed.

In the rehabilitation medicine literature, rather than measuring the physical activities that a person engages in, it is more common to assess ability to independently perform activities of daily living and measures of more distal outcomes such as community integration. The problem is that even if someone is able to do an activity (e.g., walk $1 / 4$ mile), this does not mean that they regularly do that activity (e.g., they may spend a half-hour walking each day or they may never spend time walking). Future opportunities that would enhance a rehabilitation medicine-public health collaboration could include measures that assess both functional capacity and ability, as well as regular physical activity that individuals regularly undertake. Dimensions of physical activity should include the types, duration, frequency, and intensity of the physical activities in which people with disabilities engage [30].

Objective measures of physical activity, such as pedometers and accelerometers, can detect all types of activity. However, these monitors are typically worn on the waist and were developed to measure lower extremity movement so may miss activities done by persons in wheelchairs, including upper body activity or users of assistive devices [37]. Some pedometers use accelerometer-type mechanisms that may make them more accurate in populations with gait problems 
but more commonly spring-levered pedometers are used, and these may not be accurate in those with mobility disability $[38,39]$. The Step Watch Activity Monitor is worn on the ankle and has been shown to be more sensitive for those with slow or abnormal gait patterns [30, 40, 41].

Research supports the use of waist-worn accelerometers in populations with MS [42]. Some researchers have used wrist-worn accelerometers to capture upper-body movement in populations with spinal cord injury [30]. However, the equations used to determine the intensity of activity with accelerometers are based on healthy adults and may not be valid to use for older adults and those with mobility disabilities who move differently and often use assistive devices [30].

Activity and participation have also been assessed in persons with disability using newer technologies. The Participation and Activity Measurement System integrates selfreported data with wheel revolution counters, seat sensors, and GPS to capture activity data for people using wheelchairs [43]. Such systems could be adapted and applied to older adults who use walkers or other assistive devices. Other researchers are developing systems that integrate data from GPS and accelerometers in populations of older adults and those with disabilities (Physical Activity Location Measurement System [44]; Movement and Activity in Physical Space (MAPS) score [45]). The home is a setting where technology may be helpful in measuring physical activity objectively. Sensors are being developed that can be installed in homes to assess activity patterns within the home [46].

Additional research on the measurement of physical activity for populations aging with mobility disability is needed on several fronts. One is that it is imperative to include measures of physical activity in studies of persons aging with mobility disabilities. Another is that determining the best objective and self-reported measures of physical activity for individuals aging with mobility disability will be important. Integrating measures of functioning and physical activity could be an improved measurement approach. Further examination of the equations used to derive energy expenditure for persons aging with mobility disability is also needed. The use of newer technologies, such as GPS and home sensors, to examine physical activity patterns holds promise.

3.2. Health Benefits of Physical Activity for Older Adults with Mobility Impairment. Improving physical activity in an aging population helps to prevent mobility disability. Much of the research conducted in this area excludes those that already have mobility disability [47]. For persons who already have a disability, adopting a physically active lifestyle can help prevent or control secondary conditions as well as further declines in functioning and further loss of mobility. Because persons with mobility disability are at higher risk for secondary conditions that physical activity can prevent, adopting a physically active lifestyle could potentially result in greater health benefits among persons with disability [48]. For example, among persons with spinal cord injury, cardiovascular disease has replaced urinary complications as the leading cause of death [10].
3.2.1. Health Benefits. Generally, the health benefits of an active lifestyle among persons with disabilities appear to be similar to populations without disability. Research conducted on individuals with disability has shown physical activity to positively affect hypertension, manage cardiovascular disease and osteoarthritis, and reduce spasticity $[47,49$, 50]. There is moderate evidence that physical activity reduces secondary conditions prevalent in persons with mobility disabilities, including pain and fatigue [20]. Mortality in people with CHD is related to low fitness [23].

Due to a lack of studies, evidence is limited that physical activity improves healthy weight and metabolic health among persons with mobility disabilities. There is some evidence that physical activity improves weight and metabolic factors among persons with SCI [51] and arthritis [52]. One difficulty in examining relationships between physical activity and weight among persons with disabilities is that BMI is not always obtained or BMI calculations are not straightforward (e.g., persons with amputations where the weight of the missing limb must be accounted for to determine current BMI). Few studies have collected weight status or BMI information and physical activity data among populations with mobility disability.

3.2.2. Physical Functioning Benefits. Research conducted on individuals with disability has shown physical activity to increase overall fitness and prevent functional decline [47, $49,50]$. In particular, research suggests moderate to strong evidence that aerobic exercise improves cardiorespiratory fitness in persons with lower limb loss, MS, stroke, and SCI, and walking speed and distance in persons with stroke and MS [3]. Exercise also was noted to improve physical function and delay disability among those with osteoarthritis and rheumatic conditions [3]. There is moderately strong evidence that resistance training improves muscular strength in persons with stroke, MS, and SCI [3]. Motl recently reviewed studies on MS and physical activity showing that exercise training improved walking mobility with a weighted mean effect size of (.19), similar to that of medical interventions [53]. A Cochrane review of physical fitness interventions for stroke found that cardiorespiratory interventions that included walking resulted in improved walking speed, endurance, and reduced dependence while walking [54]. Another review found that physical rehabilitation programs were effective in improving physical state, including functioning with ADLs, flexibility, and strengthening [55].

3.2.3. Mental Health Benefits. Research conducted on individuals with disability has shown physical activity to improve quality of life and reduce depression $[3,47,49,50]$.

3.2.4. Cognitive Health Benefits. Research shows that exercise interventions can improve cognitive functioning among people with existing mild cognitive impairment [56]. A promising avenue of future research is to examine whether exercise interventions can improve cognitive function among persons with mobility disability who are at risk for cognitive impairments as they age, such as those with MS. There is 
some cross-sectional evidence that people with MS who are more active report fewer cognitive deficits [57].

3.2.5. Other Findings. The committee report from the 2008 Physical Activity Guidelines [3] summarized evidence for the health benefits of exercise for persons with disabilities. A main finding was that physical activity is safe and effective for people with disabilities. Few adverse outcomes were reported. The report concluded that research evidence is lacking regarding: (1) the dose of physical activity needed to confer health benefits, and (2) longitudinal studies on the health benefits of physical activity among persons with a variety of disabling health conditions.

An understudied area of concern is the health effects of prolonged sedentary behavior in persons aging with mobility disabilities. Even when adults meet physical activity guidelines, sitting for prolonged periods can compromise metabolic health. Television time, even after adjustment for physical activity, is independently associated with increased risk for obesity, type 2 diabetes, CVD mortality, and all-cause mortality $[58,59]$. This has not been studied among populations with disability. Further evidence of the relationship between television watching and health outcomes among persons with disabilities is needed. There is evidence that adults over 60 spend more time watching television than other age groups [60, 61]. Greater television use was related to lower life satisfaction among older adults in one study [60].

Overall, there is a dearth of research on the health benefits of physical activity among persons aging with mobility disabilities. Larger studies, focusing on specific diseases (e.g., MS) and cross-cutting conditions (e.g., mobility disability related to cardiovascular disease, diabetes, etc.), can better elucidate the health benefits of physical activity. Additionally, more focus on the health effects of light intensity activities [62] and their relationship to health outcomes is needed among those aging with mobility disability. More research is needed on specific health benefits of physical activity, which are under-examined among persons aging with mobility disability and may show promising relationships (e.g., variables such as weight status, progression of illness, mental health, and cognitive functioning).

\subsection{Factors That Influence Participation in Regular Physical} Activity. Few cross-cutting studies address correlates of physical activity among people aging with mobility disability. We discuss the studies that have examined the demographic, physical health, psychological, social, and built environment variables that are correlated with physical activity among various groups with mobility disability.

3.3.1. Demographic Correlates. Sociodemographic correlates of physical activity have been understudied among persons with disabilities. Younger age has been related to less physical activity among people with SCI [25]. People with MS have been shown to be less active if they had a disability pension and children to care for [63]. Among people with arthritis, relationships with sociodemographic variables have been inconsistent or nonexistent $[64,65]$. Among those with
CHD, age, BMI, education, income, and insurance coverage were not related to physical activity while being Caucasian, male, and employed were associated with higher levels of exercise [23]. The lack of studies may be due to the use of study samples that are not diverse with respect to various sociodemographic indicators.

3.3.2. Physical Health Correlates. Common health-related correlates include pain and fatigue for those with SCI (shoulder pain; [66]), MS [67], arthritis [64], and stroke (fatigue [68]). Among people with SCI, independent predictors of greater physical activity were less time since injury, being a manual wheelchair user, and having motor complete paraplegia [25]. Predictors of greater physical activity in people with MS were less severe disease [63] and less difficulty walking $[69,70]$. Controlling for disease severity, greater MS-related symptoms predicted less physical activity cross-sectionally [69] and longitudinally over a three- to five-year period [70]. In one study, the relationship between greater symptoms and lower physical activity was through greater fatigue [71]. Illness-related barriers limited physical activity in a sample of women with arthritis and included pain, stiffness, and arthritis limitations on the body's ability to do activity [72]. In a different sample of persons with arthritis, those who were more active had fewer medical comorbidities and less obesity [52]. Arthritis, fatigue, and discomfort were the largest barriers to exercise among the total sample but affected those with lower physical activity levels more [52]. In an arthritis physical activity program, disease exacerbations were a barrier to exercise [73]. High rates of fatigue impacted participants with COPD undergoing pulmonary rehabilitation [74]. In those with CHD, higher functional status and better health status including fewer comorbidities and less severe illness were related to higher levels of physical activity [23].

3.3.3. Psychological Correlates. There are several common psychological correlates of exercise. Higher self-efficacy has been related to higher physical activity among people with SCI [75], MS [28], arthritis [52, 64], CHD [23], and diabetes [76]. Exercise enjoyment, outcome expections, and sense of personal accomplishment have been found to be related to more physical activity among those with MS [28, 77]. The benefits of exercise and positive attitudes were found to be related to more PA among persons with arthritis [64]. Higher previous physical activity level, greater intentions to exercise, positive attitudes, and benefits were related to more exercise in CHD [23]. Emotional distress including depression has been an important barrier to exercise among persons with SCI [78], MS [67], stroke [68], CHD [23], and arthritis [64]. Physical exertion was the greatest barrier to physical activity among both exercisers and nonexercisers with MS [79]. Other barriers that have been cited among older adults with functional limitations or physical disabilities include mistaken beliefs that exercise must be vigorous and uncomfortable to afford health benefits [80]. Barriers to exercise in persons with arthritis have included time constraints, boredom, lack of knowledge, and lack of motivation [64]. 
3.3.4. Social Correlates. Social isolation has been shown to be a barrier to physical activity among persons with stroke [68]. Encouragement to be active from others, including family, friends, and medical providers, has been related to physical activity in persons with arthritis [52, 64]. More social support resulted in higher exercise during and after cardiac rehabilitation for those with CHD [23].

3.3.5. Environmental Correlates. The ICF framework states that the environmental context includes products and technology, natural environment and human-made changes, support and relationships, attitudes, and services, systems, and policies [7]. The built environment, including humanmade structures (e.g., sidewalks, street crossings) in cities, landscapes, and buildings [81], may be particularly important in shaping physical activity as those with existing impairments can become more disabled by limiting conditions in the built environment $[82,83]$.

Research on built environment features shows that having access to public transportation is important for promoting recreational physical activity among those with physical disabilities [84], MS [85], CHD [23], and knee osteoarthritis [86]. Having low-cost programs has been shown to be important for those with physical disabilities [84], MS [85], CHD [23], and arthritis [64, 72]. Additional important built environment variables are having convenient access to destinations and fitness programs for physical activity [64]. Studies have shown that destinations and accessibility are important for promoting physical activity. Specifically, destinations for those with MS [85], arthritisspecific exercise programs at local fitness facilities as well as parks and trails among women with arthritis [72], parks and walking areas for those at high risk or who had knee osteoarthritis [86], distance and accessibility of cardiac rehabilitation programs for those with CHD [23], and accessibility to stores and buildings among people with SCI [78]. Specific built environment barriers to exercise have included weather, poor sidewalk conditions, lack of streetlights, and safety concerns among women with arthritis $[64,72]$. Weather was not associated with exercise in people with CHD undergoing cardiac rehabilitation [23]. Crime rates have been associated with lower physical activity among persons with SCI [87]. Additional environmental barriers to physical activity among persons with physical disabilities include lack of curb cuts, inaccessible access routes, narrow doorways, slippery floors, lack of handrails on stairs, lack of adaptive or accessible equipment in fitness facilities, lack of information on facilities and programs that are accessible, and unfriendly environments at fitness facilities [84].

There are few studies that measure both the environmental context for physical activity and physical activity levels among persons with disabilities. Few detailed selfreported measures of the built environment are validated for use among those with disabilities. Some have related environmental features to participation, activity ability, and quality of life among persons with SCI [88] and general rehabilitation populations [89]. Relationships were observed between home and community environment and participation as well as quality of life. One study suggested that over time the relationships diminish as people adapt to or modify their environment [89].

One methodologic issue in these studies is that many built environment features (e.g., walkability, transit access, nearby destinations) are expected to more highly relate to active transport (e.g., walking or wheeling to get to useful destinations like stores or a bank) rather than the more commonly studied recreational physical activity (e.g., walking or wheeling for leisure) [90]. Features expected to be more related to recreational physical activity include aesthetics and traffic safety. Studies to date have not examined relationships of these specific types of physical activity and built environment features in persons with mobility disabilities.

Environmental avoidance can also affect mobility among persons aging with disabilities [91]. Fear of going outdoors can interact with the local built environment features in ways that further inhibit activity (e.g., barriers in the built environment) [92] or help people overcome their fears (e.g., presence of facilitators in the built environment). The importance of addressing multiple levels of influence on physical activity in future studies is highlighted by these results.

More research is needed describing individual, psychological, social, and built environment correlates of physical activity among persons aging with mobility disability. Perhaps one reason for the dearth of research in these areas relates to the focus of medical rehabilitation on remediation of physical impairments and regaining the ability to carry out activities of daily living, a focus that is largely driven by insurance reimbursement. Outcomes measurement in rehabilitation has reached beyond measuring impairment and disability to encompass environmental determinants of societal participation. However, it is telling that measures of environmental factors within rehabilitation, such as the Craig Hospital Inventory of Environmental Factors, have not been widely used [93]. Medical rehabilitation research has also been limited by an over-emphasis on individual and condition-specific levels of analysis rather than on population-based perspectives and issues that transcend disability types, such as problems attributable to inactivity and sedentary behaviors. This is understandable given that rehabilitation often deals with complex and relatively rare conditions such as spinal cord injury and multiple sclerosis. Increased awareness of environmental barriers to mobility with the aging of the population and renewed interest in the health benefits of physical activity may benefit disability populations indirectly through policy changes and research on universal health promoting activities.

While research on physical activity is increasing among populations with disability, particularly those with MS, there are many cross-cutting conditions (e.g., mobility disability) and specific conditions (e.g., spinal cord injury) that are understudied in terms of physical activity correlates and determinants. Correlates of physical activity among persons with mobility disability may include a combination of general barriers faced by the general population (e.g., lack of time) and barriers specific to the condition or disability (e.g., arthritis-related pain). Among those with 
the various disabilities described, common correlates include pain, fatigue, depression, and self-efficacy. Some research suggests that mental health and built environment variables are related to physical activity but more data are needed, and interventions will need to target these barriers.

\subsection{Interventions and Policies to Promote Physical Activity in} Older Adults with Mobility Impairments. Interventions can target individuals, either one-on-one or in group settings, to promote changes. Another intervention approach, however, is to change the built environment and create policies to make healthy choices, including active living, the default option (e.g., walking to the store rather than driving there) [94]. We briefly review current research on each of these areas.

\subsubsection{Individually Focused Physical Activity Interventions.} Maximizing mobility in older adults has been the focus of multiple intervention projects. Much of the focus has been on preventing mobility disability in otherwise healthy older adults (e.g., [95]). However, some interventions have been specifically developed to increase physical activity among those who have mobility disabilities.

The research that has been done among older adults with chronic disease or low fitness has indicated that multicomponent programs (including endurance, strength, flexibility, and balance) focusing on physical activity only (versus multiple behavior targets such as activity, nutrition, and medication), building exercise slowly over time, and using behavior change principles (e.g., social support, health contracts, self-monitoring, goal-setting) help promote physical activity [96-100]. Effective physical activity programs among older adults target moderate intensity activities, are inexpensive, are convenient [80], can be done independently though with some instruction [101], and are tailored [102]. For women, particularly, inclusion of a social component can be important [80]. It is likely for older adults with mobility disability that these program characteristics are also important although there may be differences due to the higher rates of illness, pain, fatigue, and depression among those with mobility disabilities.

Rimmer and colleagues conducted a review of exercise interventions specifically for individuals under age 65 with physical and cognitive disability [6]. MS and stroke were the most common conditions studied. The 32 randomized controlled trials involved aerobic, strength, or combined exercise but no two trials offered the same dose across 11 different disability groups, making comparison difficult. The primary outcomes were functional, musculoskeletal, cardiorespiratory, mental, and metabolic health. Although many of the exercise trials showed positive benefits, the lack of replication and often small sample size makes conclusions difficult. The authors suggest that exercise interventions need to be developed that focus on groups with the same functional impairment or activity limitation (e.g., inability to walk) and varied doses of exercise [6].

It can be difficult to evaluate whether exercise interventions result in increases in exercise. Motl's review of studies on MS and physical activity showed the largest effect sizes were for studies with supervised exercise and shorter duration programs [103]. Petter et al.'s review on physical activity programs for CHD showed that exercise levels did not vary whether the program was home or hospital based [23]. Several limitations of the rehabilitation research literature are (1) lack of measurement of physical activity and (2) use of time-limited structured programs such that the benefits likely end when the programs stop. Studies are needed that focus on improving lifestyle activity and participation in on-going exercise programs that can be maintained once research ends.

Barriers to activity can be much higher than for populations without disabilities, stemming from both increased internal struggles (e.g., motivation, pain, depression) and environmental constraints (e.g., lack of access to exercise facilities). Strategies to improve self-efficacy for continuing to exercise as well as self-efficacy to overcome barriers to exercise (symptoms, social environment, and physical environment) may merit specific attention in trials to promote physical activity in people with MS and other mobility disabilities [104, 105]. Social support has been identified as an important component of adapting to chronic conditions [89] and could be a means for encouraging a physically active lifestyle.

Pacing of activity may be important to promoting physical activity among persons aging with mobility disability. Brawley et al. noted that in one large intervention for knee osteoarthritis, those who exercised more often but for shorter durations per session had less pain and better ADL performance than those who did more exercise [80]. This suggests that for persons with disabilities, doing shorter bouts of exercise regularly could be more beneficial than pushing oneself to do more at one time. Additionally, the physical activity guidelines state that activity can be accumulated with three 10-minute bouts throughout the day and health benefits can still occur [20].

An important issue is assuring older participants of the safety of exercise. Older adults or those with mobility disability may not believe that exercise is safe for them or they may not consider activities they can do (e.g., slow walking with an assistive device) a valid form of exercise [80]. Risk of falls and fear of falling need to be addressed via education and specific intervention targets. Additionally, falls prevention among people aging with mobility disabilities is important due to higher rates of falls among those with disabilities [106]. Fall rates for those with disabilities may be twice the rate of community-dwelling older adults [106]. A potential cause and consequence of falls is activity restriction which can lead to a decrease in quality of life [106]. Physical activities consisting of balance training, strengthening exercises, and gait training are important elements of falls prevention programs. However, there are few falls prevention interventions geared towards those with mobility disabilities [106]. Programs developed in the general aging population, such as Matter of Balance and Stepping On, could be tested to determine whether they are effective for persons with mobility disabilities [106]. Some attempts at modifying fall prevention programs for populations with disability, such as stroke, have begun [107]. A review of interventions 
to prevent falls in those aged $\geq 80$ found that the most cost effective intervention included strength and balance retraining [108].

Evidence-based physical activity programs do exist for some populations of adults aging with mobility disability. The EnhanceFitness program, for example, has been offered to adults over age 65 in community-based settings, and many participants have chronic illnesses that make them susceptible to disability [109]. The program promotes social support for a healthier lifestyle and involves supervised moderate intensity aerobic exercise, strength training, and flexibility and balance training. Involvement in the program was found to decrease health care costs over the long term [109]. Fit and Strong is an evidence-based program for people with arthritis consisting of 8 weeks of aerobic, flexibility, and resistance training exercises. Because maintenance of physical activity is a problem when structured programs end, Fit and Strong tested the use of a maintenance contract plan according to individual preferences and telephone contacts twice monthly for months 3 through 6 and monthly between months 7 and 18 [110]. This approach was shown to promote physical activity, decrease lower extremity pain, stiffness, improve function, and improve strength and aerobic capacity as well as decrease depression at 18 months [110]. For those with arthritis, other evidence-based programs include the Arthritis Foundation Aquatic Program [111], People with Arthritis Can Exercise (PACE) [73], and Walk with Ease [112]. A problem is that participation in such structured programs has been noted to be low, around 1\% of the target population in one instance [73]. Several reasons why people may not attend such programs are lack of interest in groupbased exercise programs, inability to access programs due to transportation and lack of knowledge the programs are offered in close proximity to ones' residence. Improving the reach of such programs and expanding them to include those with various types of mobility disability should be a target.

The Chronic Disease Self-Management Program is an empirically supported program teaching self-confidence to manage chronic conditions for those with hypertension, arthritis, heart disease, stroke, lung disease, and diabetes [113]. Exercise is one component of the program and has been shown to improve for those that participate. While those with mobility disabilities could be included in such programs, further translating this type of approach for those specifically with diverse types of mobility disabilities could be a promising strategy.

Some studies have sought to provide cognitive-behavioral self-regulation skills to aid participants' transitions from rehabilitation to independent lifestyle activity [80]. Programs comparing facility-based programs to home-based independent exercise programs have shown no difference in improvements in functional capacity, suggesting that a lifestyle, home-based approach can be as effective as facilitybased treatments. Lifestyle physical activity programs, which incorporate routine activity as part of usual life, may be more acceptable to a larger population [114]. Some researchers are beginning to investigate the utility of such approaches [114].

Notably, while Internet-based and technology-based interventions are becoming increasingly popular to use among many populations [115], including some with chronic illness (e.g., diabetes [116]), these approaches are under-studied among persons aging with mobility disability. Exergame (i.e., active video games) interventions are being used for rehabilitation purposes [117], including balance training [118] and upper limb strengthening among persons with stroke [119], but have not been empirically tested as a physical activity promotion tool among persons aging with mobility disability. Virtual reality and exergames are promising because they can promote social engagement as well as improvements in mental health, cognitive health, specific rehabilitation needs, and physical activity $[120,121]$. Additionally, interventions to decrease sedentary behaviors such as television viewing among persons with mobility disability are nonexistent.

In sum, based on evidence with older and less active populations and those with general disabilities, programs for those with mobility disability will likely need to target multiple components. To address risk of falls, lifestyle physical activity interventions may not be enough and specific exercises to improve strength and balance may be needed. In this case, structured, community-based exercise programs are needed for people aging with various types of mobility disability. However, issues such as pain, fatigue, and depression may make it more difficult to engage persons with mobility disability in such programs. Therefore, promoting low-intensity, unstructured, lifestyle activity, although underutilized, may be a viable strategy among individuals with mobility disability coping with barriers to moderate to vigorous activities. Researchers need to focus on participation in community-based programs as well as lifestyle activity changes and decreased sedentary behavior.

3.4.2. Environmental and Policy Interventions. Intervention approaches to physical activity recommended by the Guide to Community Preventive Services include enhanced access to places for physical activity combined with informational outreach, community-scale urban design, and street-scale urban design (e.g., street crossings, traffic calming, sidewalks) [122]. Research now acknowledges the effect of the built environment on persons with mobility disability [123], but no intervention research focuses on addressing the neighborhood built environment barriers among persons with disabilities. Yet, to promote healthy aging, it is important that environments and communities support the integration of people aging with mobility disability to enhance opportunities for active living.

Longitudinal evidence shows that street conditions affect mobility more among persons with mobility disability than those with mild or no physical impairments [82]. Improving street quality could lead to more use of the local neighborhood for utilitarian and recreational activities. This could slow or reverse the disablement process among adults with the greatest risk for disability in outdoor mobility [82].

Another relevant neighborhood characteristic relates to safety and neighborhood deprivation. Lang et al. [124] conducted a prospective cohort study with a two-year followup and found that older people living in deprived neighborhoods (based on income, employment, education, living 
environment, health deprivation, and crime) are significantly more likely to experience incident mobility difficulties than those in less-deprived neighborhoods. Persons with disabilities may feel less safe ambulating around their communities due to believing that they are perceived as easier targets for crime. Crime reduction efforts should explicitly focus on improving safety concerns among persons aging with mobility disability.

Beyond neighborhood-level environmental considerations, home environments can either support or hinder mobility [89]. Accessible features allow for people, regardless of functional status, chronological age, or use of mobility devices to have easy access to and use of their home. The home can be an important source of physical activity through the ability to do exercise or activities of daily living and to limit time spent being immobile. Research has examined home modification but more towards preventing injury and falls and increasing functioning and activities of daily living [125] rather than with a view towards promoting physical activity (e.g., by providing exercise equipment).

Some studies have used interventions that combine cognitive behavioral approaches and address the environment. Cognitive-behavioral strategies, finding supportive environmental solutions, exploring motivation postinjury, and capturing new frames of reference were found to help promote physical activity after SCI in a qualitative study [126]. Similarly, the Personalized Exercise Program for predominantly African American women with mobility disabilities and obesity included a focus on individual and cultural preferences for activity, equipment adaptations, and access to community resources and resulted in improved physical activity, reduced weight, and decreased barriers to activity [127]. Such interventions are encouraging that more work is needed to address multiple levels of influence on physical activity (e.g. individual, social-cultural, and built environment) [127].

With the advent of the Americans with Disabilities Act (ADA), newer construction and retrofitting of older construction can lead to improved mobility in public buildings and spaces but has yet to reach our private homes. The opportunity to use universal design (UD) features in the design of homes as well as communities will be increasingly important as the population ages. UD features are intended to be accessible, attractive, and acceptable to everyone [128]. It will be important for urban planning policies to promote new housing designs and developments that are accessible to all as the population ages and rates of disability increase.

The Environmental Protection Agency (Building Healthy Communities for Active Aging [129]), World Health Organization (Global Age Friendly Cities [130]), and AARP (Planning Complete Streets for An Aging America [131]) sponsor initiatives encouraging communities to be designed for healthy active aging that each touch on issues related to persons aging with disabilities. The Federal Administration on Aging, Evidence-based Disease, and Disability Prevention Program has provided over $\$ 23$ million since 2003 to support community-based healthy aging programs in 24 states [132]. The programs include physical activity and falls prevention programs. These programs have served over 44,000 seniors and the number benefitting each year has been increasing. Despite the success of these programs, it remains unclear whether they will be sustainable either by creating an adequate business model or by convincing states to commit to long-term funding.

Because states depend on funding from the federal government to support these programs, securing policies that provide investment at the federal level should be a target. Promising policy avenues that could lead to improved federal funding include the emphasis on prevention and wellness in the 2010 Patient Protection and Affordable Care Act. There will be opportunities for grants to provide funding for programs that deliver evidence-based services. As part of healthcare reform, Medicare and Medicaid beneficiaries will be incentivized to complete behavior modification programs. Promoting dissemination of physical activity programs targeting people with disabilities and those that use Medicare and Medicaid should be an important objective for these funds.

There are increasingly more technical assistance opportunities available targeting cross-sector groups related to environmental and policy change for mobility. One such initiative is the Environmental and Policy Change for Healthy Aging [133] (http://agingfriendly.org/), a novel online initiative of on-demand presentations, archived webinars, a clearinghouse for mobility resources, and an active online community. The initiative focuses on the challenges amenable to environmental and policy change, the evidence that supports specific approaches and their outcomes, and promising strategies for practice.

Overall, there are few physical activity interventions from which to draw conclusions on the most effective ways to promote activity among persons aging with mobility disability. It is likely that the best approaches to promoting physical activity will use an intervention framework that incorporates both the physiologic process involved in disability, psychosocial barriers (e.g., self-efficacy), as well as the role of the environment. Several frameworks are available to guide intervention approaches. A widely used model in physical activity and public health research is the ecological model, which promotes intervention at the intrapersonal (biological/psychological), interpersonal/cultural, physical environment, and policy levels of change (i.e., multilevel approaches) [90]. Additionally, Webber et al. [134] created a mobility framework for older adults meant to bridge various disciplines. The model incorporates the seven dimensions of lifespace (e.g., room, home, outdoors, neighborhood), mobility determinants (including cognitive, psychosocial, physical, environmental), and gender, culture, and biographical influences.

There are many models of disability which are also important to consider including the the biopsycho-ecological paradigm [135], Nagi's disablement model [9], the International Classification of Functioning [7], and Verbrugge and Jette's disablement process model [9]. These frameworks all embrace a biopsychosocial view of disability and acknowledge that disability is not only determined by impairments or functional limitations within an individual, but rather an interaction between individuals and contextual factors [7-9]. 
Several relevant frameworks of disability have been reviewed elsewhere $[9,136]$.

Regardless of the model used, the built environment appears to be an important barrier to mobility and physical activity in persons with mobility disability. Thus, interventions will need to address built environment influences. Making changes to the built environment, by retrofitting and encouraging policies that use UD for new developments, is a promising approach to helping people stay active as they age with a mobility disability.

\section{Discussion}

The population of individuals aging with mobility disability is increasing and current research on physical activity to promote health and reduce secondary conditions is limited. In this review, we provide several recommendations that will help build a research agenda targeting physical activity promotion among persons aging with mobility disabilities (see Table 1). Our review, while not systematic, is intended to provide a broad overview and address limitations and barriers of research to date so that future endeavors can further the field of research.

Evidence shows that physical activity levels among persons with mobility disability are lower than the general population though information on subgroups of disability type is lacking. Improved surveillance system assessment of various disability types as well as improved measures of selfreported and objective physical activity assessment will help researchers better understand patterns of physical activity among those aging with mobility disability. Several new technologies can help guide measurement and understanding of physical activity and mobility patterns, including GPS and sensor technology.

Evidence illustrates that even among those with disabilities, physical activity can reduce secondary chronic conditions, reduce pain, and improve physical function [2]. Research on the benefits of physical activity among persons aging with mobility disability has lacked longitudinal studies and examination of important potential health benefits such as cognitive function. Correlates of physical activity among persons aging with mobility disabilities are also understudied. There are no review studies that comprehensively address correlates of physical activity for persons aging with mobility disabilities. Little is known regarding the interaction of gender, ethnicity, socioeconomic status, and mobility disability as people age. Particularly important individual barriers to exercise include pain, fatigue, and depression; the community built environment is an additional barrier. Physical activity interventions will need to target each of these concerns and multilevel approaches should be used.

There are several special concerns for a research agenda targeting persons aging with mobility disabilities that crosscut each of the four areas covered here. One issue is that there is a lack of clear prevalence and trend data on physical activity patterns in this population, making it difficult to fully understand the scope of the problem, identify relevant correlates, and develop effective interventions. Healthy People 2020 contains an objective related to including identification of people with disabilities in datasets [16]. The report notes that only 2 of 26 datasets identified persons with disabilities in Healthy People 2020, and the objective is to double the number of datasets that identify persons with disabilities. Indeed, in datasets from Healthy People 2010, data are not available for persons with disabilities regarding relevant outcomes including television viewing and walking for transportation [22].

Another problem is that clear physical activity objectives and guidelines are lacking for persons aging with mobility disability. Such specific guidelines can be useful for tracking physical activity patterns and developing intervention targets which could include provider-based recommendations. Due to a lack of research focus on those aging with mobility disability, determining adequate doses and types of physical activity necessary to confer health benefits has not been possible. One promising step forward is that Healthy People 2020 includes a physical activity objective for older adults with reduced physical or cognitive function [16].

A theme observed in the research described here is that community-based exercise programs targeting persons with various types of mobility disability are lacking. There is evidence that rehabilitation programs may effectively increase physical activity levels among participants, but once the programs end, levels decline. It would be helpful for rehabilitation practitioners to refer their discharged patients to relevant community-based physical activity programs, but these programs are not widely available, with the possible exception of those for persons with arthritis. However, even these empirically validated programs are underused. Research can help improve our understanding of what program characteristics will be effective in promoting physical activity for persons aging with mobility disability. More knowledge is needed regarding preferred settings for doing exercise (e.g., home, general group, or group of persons with the same impairments), modes of exercise (alone or with others), and types of exercise (e.g., walking, chairbased aerobic). Physical activity programs and interventions will need to include safeguards that address the fluctuations in activity due to illness or other setbacks. Other underexamined intervention targets relevant to promoting physically active lifestyles include reducing sedentary behaviors such as television watching.

An additional research difficulty is that physical activity research on people with mobility disability has often been discipline and disease specific [134]. Generally, there is a need to focus away from specific conditions (e.g., amputation) and toward broader categories of impairment (e.g., lower extremity mobility impairment). Larger studies can then be conducted and the population of persons aging with mobility disability can be a growing target for largerscale public health surveillance, prospective studies, and interventions [137]. Many older adults have more than one chronic illness or disability, so disease-specific research is less useful, and often those with comorbid conditions are excluded from research studies. Cutting across conditions would allow research to keep individuals with comorbid conditions in research studies rather than exclude them. In order to prepare for an aging society, we need to learn more 
TABLE 1: Recommendations for research priorities related to promoting physical activity for adults aging with mobility disabilities.

Topic Area $\quad$ Recommendations

(i) Define mobility disability and employ standard definition across sectors and research studies. Include specific categories of disability (e.g., mobility disability,

(1) Prevalence of physical activity among older populations with mobility disability sensory disability) in surveillance

(ii) Conduct studies on best means for measuring physical activity among persons aging with mobility disability, including objective (pedometers, accelerometers) and subjective measures

(iii) Incorporate newer technologies to better understand physical activity patterns among persons aging with mobility disability (Global Positioning Systems; home-based sensors)

(i) Conduct research on ways physical activity benefits persons with mobility disabilities as they age, including larger samples, more rigorous methods, and prospective studies

(2) Health benefits of physical activity and consequences of sedentary behavior in older adults with mobility disability (ii) Conduct studies that use the same measurement tools, capture data on frequency, intensity, duration, and modality of exercise so that recommendations for people with mobility disability can be developed

(iii) Include understudied health outcomes such as weight status, mental health, and cognitive functioning

(iv) Examine the effects of sedentary behaviors among those aging with mobility disability

(v) In rehabilitation-oriented, supervised or structured physical activity interventions, include explicit measurement of physical activity among populations with mobility disability (versus assessment of only ability)

(i) Expand studies on the correlates of physical activity participation in this population to include demographic, societal, mental health, and built environment variables

(ii) Develop measures of individual, social, and environmental facilitators and barriers of physical activity common among persons aging with mobility disability (iii) Conduct studies that include both specific disability groups (e.g., aging with spinal cord injury) and broader groups with the same activity limitation (e.g., aging with mobility disability)

(i) Develop and test interventions that use multilevel approaches (which aim to target individual, interpersonal, and built environment factors) to promote physical activity among persons with mobility disability

(ii) Interventions should address symptoms such as pain, depression, and fatigue that are common among persons aging with mobility disability and that are barriers to being physically active

(iii) Conduct technology-based interventions (e.g., using Web-based approaches, exergames, feedback from GPS and other technologies) to promote physical activity (iv) Conduct studies assessing the effectiveness of lifestyle-based, lower intensity activity programs that address features of the home design and built environment in conjunction with structured programs

(v) Develop community-based physical activity programs for persons aging with mobility disability

(vi) Further develop and continue policies and funding at the local, regional, and national level to support evidence-based environmental enhancements and universal design about populations with comorbid chronic conditions and disabilities [138].

The importance of the built environment, both in the neighborhood and the home environment, as a barrier to activity among persons aging with mobility disabilities is clear and needs to be further elucidated and measures of these constructs are needed. Employing ADA standards and UD principles will be important so that an aging society can find acceptable housing and communities that allow them to stay active as they become unable to drive. Healthy People 2020 targets both persons with disabilities and older adults as important populations that need supportive built environments [16].

In sum, there is a dearth of research on promoting physical activity among persons aging with mobility disability. Due to a population that is aging with more disease and disability [14], there is a need to better understand preventive health behaviors including physical activity in aging populations with disability. Promoting physically active lifestyles to enhance mobility, even among those with disability, as a preventive and control strategy is imperative. Individuals with disabilities have traditionally been treated 
by medical professionals in rehabilitation medicine, but with the aging demographic and associated increase in disability, public health approaches will likely be necessary due to cost restraints [2]. Public health research efforts should attempt to learn from rehabilitation research and vice versa, forming a new field of public health rehabilitation. Developing effective physical activity interventions and designing our communities to support active aging for all is vital.

\section{Acknowledgments}

B. Belza is partially funded by the Prevention Research Centers Program of the Centers for Disease Control and Prevention through a cooperative agreement with the Universifty of Washington Health Promotion Research Center, cooperative agreement \#U48DP001911. C. H. Bombardier has funding from the Northwest Regional Spinal Cord Injury System, Grant H133N060033, the National Institute on Disability and Rehabilitation Research, Office of Special Education and Rehabilitative Services, US Department of Education. D. E. Rosenberg is funded by the NIH Kirschstein NRSA Award, Grant 2T32HD007424-19.

\section{References}

[1] T. E. Seeman, S. S. Merkin, E. M. Crimmins, and A. S. Karlamangla, "Disability trends among older Americans: national health and nutrition examination surveys, 19881994 and 1999-2004," American Journal of Public Health, vol. 100, no. 1, pp. 100-107, 2010.

[2] M. Brault, J. Hootman, C. Helmick, and K. Theis, "Prevalence and most common causes of disability among adultsUnited States, 2005," Morbidity and Mortality Weekly Report (MMWR), vol. 58, no. 16, pp. 421-426, 2009.

[3] Physical Activity Guidelines Advisory Committee, Physical Activity Guidelines Advisory Committee Report, 2008, U.S. Department of Health and Human Services, Washington, DC, USA, 2008.

[4] The Healthy Aging Research Network Writing Group, "The prevention research centers healthy aging research network," Preventing Chronic Disease, vol. 3, no. 1, pp. 1-7, 2006.

[5] T. Prohaska, E. Belansky, B. Belza et al., "Physical activity, public health, and aging: critical issues and research priorities," Journals of Gerontology B, vol. 61, no. 5, pp. S267-S273, 2006.

[6] J. H. Rimmer, M.-D. Chen, J. A. McCubbin, C. Drum, and J. Peterson, "Exercise intervention research on persons with disabilities: what we know and where we need to go," American Journal of Physical Medicine \& Rehabilitation/Association of Academic Physiatrists, vol. 89, no. 3, pp. 249-263, 2010.

[7] World Health Organization, International Classification of Functioning, Disability, and Health, 2001.

[8] A. Patla and A. Shumway-Cook, "Dimensions of mobility: defining the complexity and difficulty associated with community mobility," Journal of Aging and Physical Activity, vol. 7, no. 1, pp. 7-19, 1999.

[9] A. M. Jette, "Toward a common language of disablement," The Journals of Gerontology A, vol. 64, no. 11, pp. 1165-1168, 2009.

[10] M. Field and A. Jette, The Future of Disability in America, Institute of Medicine, Washington, DC, USA, 2007.
[11] H. Arksey and L. O'Malley, "Scoping studies: towards a methodological framework," International Journal of Social Research Methodology, vol. 8, no. 1, pp. 19-32, 2005.

[12] D. J. Lollar, "Public health and disability: emerging opportunities," Public Health Reports, vol. 117, no. 2, pp. 131-136, 2002.

[13] D. Mont, "Measuring health and disability," The Lancet, vol. 369, no. 9573, pp. 1658-1663, 2007.

[14] E. M. Crimmins and H. Beltran-Sanchez, "Mortality and morbidity trends: is there compression of morbidity?" The Journals of Gerontology B, vol. 66, no. 1, pp. 75-86, 2011.

[15] A. Shumway-Cook, M. A. Ciol, K. M. Yorkston, J. M. Hoffman, and L. Chan, "Mobility limitations in the Medicare population: prevalence and sociodemographic and clinical correlates," Journal of the American Geriatrics Society, vol. 53, no. 7, pp. 1217-1221, 2005.

[16] Healthy People 2020, U.S. Department of Health and Human Services, Washington, DC, USA, 2010.

[17] H. S. Picavet and G. A. van den Bos, "The contribution of six chronic conditions to the total burden of mobility disability in the Dutch population," American Journal of Public Health, vol. 87, no. 10, pp. 1680-1682, 1997.

[18] H. K. Vincent, K. R. Vincent, and K. M. Lamb, "Obesity and mobility disability in the older adult," Obesity Reviews, vol. 11, no. 8, pp. 568-579, 2010.

[19] D. E. Alley and V. W. Chang, "The changing relationship of obesity and disability, 1988-2004," Journal of the American Medical Association, vol. 298, no. 17, pp. 2020-2027, 2007.

[20] Physical Activity Guidelines for Americans, U.S. Department of Health and Human Services, 2008.

[21] J. H. Rimmer, L. A. Wolf, B. Armour, and L. Sinclair, "Physical activity among adults with a disability-United States, 2005," Morbidity and Mortality Weekly Report, vol. 56, no. 39, pp. 1021-1024, 2007.

[22] DATA2010: The Healthy People 2010 Database, National Center for Health Statistics, Hyattsville, Md, USA, 2010.

[23] M. Petter, C. Blanchard, K. A. Kemp, A. S. Mazoff, and S. N. Ferrier, "Correlates of exercise among coronary heart disease patients: review, implications and future directions," European Journal of Cardiovascular Prevention and Rehabilitation, vol. 16, no. 5, pp. 515-526, 2009.

[24] C. Tudor-Locke, T. L. Washington, and T. L. Hart, "Expected values for steps/day in special populations," Preventive Medicine, vol. 49, no. 1, pp. 3-11, 2009.

[25] K. A. Ginis, A. E. Latimer, K. P. Arbour-Nicitopoulos et al., "Leisure time physical activity in a population-based sample of people with spinal cord injury part I: demographic and injury-related correlates," Archives of Physical Medicine and Rehabilitation, vol. 91, no. 5, pp. 722-728, 2010.

[26] J. M. Hootman, C. A. Macera, S. A. Ham, C. G. Helmick, and J. E. Sniezek, "Physical activity levels among the general US adult population and in adults with and without arthritis," Arthritis Care and Research, vol. 49, no. 1, pp. 129-135, 2003.

[27] J. Bolen, L. Murphy, K. Greenlund et al., "Arthritis as a potential barrier to physical activity among adults with heart disease-United States, 2005 and 2007," Morbidity and Mortality Weekly Report, vol. 58, no. 7, pp. 165-169, 2009.

[28] R. W. Motl, E. M. Snook, E. McAuley, J. A. Scott, and M. L. Douglass, "Correlates of physical activity among individuals with multiple sclerosis," Annals of Behavioral Medicine, vol. 32, no. 2, pp. 154-161, 2006. 
[29] R. J. van den Berg-Emons, J. B. Bussmann, J. A. Haisma et al., "A prospective study on physical activity levels after spinal cord injury during inpatient rehabilitation and the year after discharge," Archives of Physical Medicine and Rehabilitation, vol. 89, no. 11, pp. 2094-2101, 2008.

[30] C. Warms, "Physical activity measurement in persons with chronic and disabling conditions: methods, strategies, and issues," Family and Community Health, vol. 29, supplement 1, pp. 78S-88S, 2006.

[31] J. H. Rimmer, B. B. Riley, and S. S. Rubin, "A new measure for assessing the physical activity behaviors of persons with disabilities and chronic health conditions: the physical activity and disability survey," American Journal of Health Promotion, vol. 16, no. 1, pp. 34-45, 2001.

[32] A. E. Latimer, K. A. M. Ginis, B. C. Craven, and A. L. Hicks, "The physical activity recall assessment for people with spinal cord injury: validity," Medicine and Science in Sports and Exercise, vol. 38, no. 2, pp. 208-216, 2006.

[33] R. A. Washburn, W. Zhu, E. McAuley, M. Frogley, and S. F. Figoni, "The physical activity scale for individuals with physical disabilities: development and evaluation," Archives of Physical Medicine and Rehabilitation, vol. 83, no. 2, pp. 193200, 2002.

[34] A. L. Stewart, K. M. Mills, A. C. King, W. L. Haskell, D. Gillis, and P. L. Ritter, "CHAMPS physical activity questionnaire for older adults: outcomes for interventions," Medicine and Science in Sports and Exercise, vol. 33, no. 7, pp. 1126-1141, 2001.

[35] R. A. Washburn, E. McAuley, J. Katula, S. L. Mihalko, and R. A. Boileau, "The physical activity scale for the elderly (PASE): evidence for validity," Journal of Clinical Epidemiology, vol. 52, no. 7, pp. 643-651, 1999.

[36] L. Dipietro, C. J. Caspersen, A. M. Ostfeld, and E. R. Nadel, "A survey for assessing physical activity among older adults," Medicine and Science in Sports and Exercise, vol. 25, no. 5, pp. 628-642, 1993.

[37] J. H. Rimmer, "Exercise and physical activity in persons aging with a physical disability," Physical Medicine and Rehabilitation Clinics of North America, vol. 16, no. 1, pp. 4156, 2005.

[38] A. P. Marsh, R. M. Vance, T. L. Frederick, S. A. Hesselmann, and W. J. Rejeski, "Objective assessment of activity in older adults at risk for mobility disability," Medicine and Science in Sports and Exercise, vol. 39, no. 6, pp. 1020-1026, 2007.

[39] E. V. Cyarto, A. M. Myers, and C. Tudor-Locke, "Pedometer accuracy in nursing home and community-dwelling older adults," Medicine and Science in Sports and Exercise, vol. 36, no. 2, pp. 205-209, 2004.

[40] K. L. Storti, K. K. Pettee, J. S. Brach, J. B. Talkowski, C. R. Richardson, and A. M. Kriska, "Gait speed and step-count monitor accuracy in community-dwelling older adults," Medicine and Science in Sports and Exercise, vol. 40, no. 1, pp. 59-64, 2008.

[41] K. F. Bjornson, B. Belza, D. Kartin, R. Logsdon, and J. F. McLaughlin, "Ambulatory physical activity performance in youth with cerebral palsy and youth who are developing typically," Physical Therapy, vol. 87, no. 3, pp. 248-257, 2007.

[42] R. W. Motl, E. M. Snook, and S. Agiovlasitis, "Does an accelerometer accurately measure steps taken under controlled conditions in adults with mild multiple sclerosis?" Disability and Health Journal, vol. 4, no. 1, pp. 52-57, 2011.

[43] F. Harris, S. Sprigle, S. Eve Sonenblum, and C. L. Maurer, "The participation and activity measurement system: an example application among people who use wheeled mobility devices," Disability and Rehabilitation, vol. 5, no. 1, pp. 48-57, 2010.

[44] K. Patrick, Physical Activity Location Measurement System, 2010.

[45] S. D. Herrmann, B. G. Ragan, C. B. Scott et al., "Development and validation of a movement and activity in physical space (MAPS) score as a functional outcome measure," Journal of Athletic Training, vol. 43, p. 2, 2008.

[46] S. N. Patel, J. A. Kientz, and S. Gupta, "Studying the use and utility of an indoor location tracking system for nonexperts," in Pervasive 2010, P. Floreen, A. Kruger, and M. Spasojevic, Eds., pp. 228-245, Springer, Berlin, Germany, 2010.

[47] J. H. Rimmer, "Health promotion for people with disabilities: the emerging paradigm shift from disability prevention to prevention of secondary conditions," Physical Therapy, vol. 79, no. 5, pp. 495-502, 1999.

[48] U.S. Department of Health and Human Services, The Surgeon General's Call to Action to Improve the Health and Wellness of Persons with Disabilities, Public Health Service, Rockville, Md, USA, 2005.

[49] S. E. Boslaugh and E. M. Andresen, "Correlates of physical activity for adults with disability," Preventing Chronic Disease, vol. 3, no. 3, p. A78, 2006.

[50] Healthy People 2010: Understanding and Improving Health, U.S. Department of Health and Human Services, Washington, DC, USA, 2nd edition, 2000.

[51] A. C. Buchholz, K. A. Martin Ginis, S. R. Bray et al., "Greater daily leisure time physical activity is associated with lower chronic disease risk in adults with spinal cord injury," Applied Physiology, Nutrition and Metabolism, vol. 34, no. 4, pp. 640647, 2009.

[52] I. Hutton, G. Gamble, G. Mclean, H. Butcher, P. Gow, and N. Dalbeth, "Obstacles to action in arthritis: a community casecontrol study," International Journal of Rheumatic Diseases, vol. 12, no. 2, pp. 107-117, 2009.

[53] R. W. Motl, "Physical activity and irreversible disability in multiple sclerosis," Exercise and Sport Sciences Reviews, vol. 38, no. 4, pp. 186-191, 2010.

[54] D. H. Saunders, C. A. Greig, G. E. Mead, and A. Young, "Physical fitness training for stroke patients," Cochrane Database of Systematic Reviews (Online), no. 4, Article ID CD003316, 2009.

[55] A. Forster, R. Lambley, and J. B. Young, "Is physical rehabilitation for older people in long-term care effective? findings from a systematic review," Age and Ageing, vol. 39, no. 2, pp. 169-175, 2010.

[56] L. D. Baker, L. L. Frank, K. Foster-Schubert et al., "Effects of aerobic exercise on mild cognitive impairment: a controlled trial," Archives of Neurology, vol. 67, no. 1, pp. 71-79, 2010.

[57] R. S. Prakash, E. M. Snook, R. W. Motl, and A. F. Kramer, "Aerobic fitness is associated with gray matter volume and white matter integrity in multiple sclerosis," Brain Research, vol. 1341, pp. 41-51, 2010.

[58] N. Owen, G. N. Healy, C. E. Matthews, and D. W. Dunstan, "Too much sitting: the population health science of sedentary behavior," Exercise and Sport Sciences Reviews, vol. 38, no. 3, pp. 105-113, 2010.

[59] D. W. Dunstan, E. L. M. Barr, G. N. Healy et al., “Television viewing time and mortality: the australian diabetes, obesity and lifestyle study (AusDiab)," Circulation, vol. 121, no. 3, pp. 384-391, 2010. 
[60] C. A. Depp, D. A. Schkade, W. K. Thompson, and D. V. Jeste, "Age, affective experience, and television use," American Journal of Preventive Medicine, vol. 39, pp. 173-178, 2010.

[61] C. E. Matthews, K. Y. Chen, P. S. Freedson et al., "Amount of time spent in sedentary behaviors in the United States, 20032004," American Journal of Epidemiology, vol. 167, no. 7, pp. 875-881, 2008.

[62] M. P. Buman, E. B. Hekler, W. L. Haskell et al., "Objective light-intensity physical activity associations with rated health in older adults," American Journal of Epidemiology, vol. 172, no. 10, pp. 1155-1165, 2010.

[63] H. Beckerman, V. de Groot, M. A. Scholten, J. C. Kempen, and G. J. Lankhorst, "Physical activity behavior of people with multiple sclerosis: understanding how they can become more physically active," Physical Therapy, vol. 90, no. 7, pp. 1001-1013, 2010.

[64] S. Wilcox, C. Der Ananian, P. A. Sharpe, J. Robbins, and T. Brady, "Correlates of physical activity in persons with arthritis: review and recommendations," Journal of Physical Activity and Health, vol. 2, pp. 230-252, 2005.

[65] C. Der Ananian, S. Wilcox, K. Watkins, R. P. Saunders, and A. E. Evans, "Factors associated with exercise participation in adults with arthritis," Journal of Aging and Physical Activity, vol. 16, no. 2, pp. 125-143, 2008.

[66] D. D. Gutierrez, L. Thompson, B. Kemp, and S. J. Mulroy, "The relationship of shoulder pain intensity to quality of life, physical activity, and community participation in persons with paraplegia," Journal of Spinal Cord Medicine, vol. 30, no. 3, pp. 251-255, 2007.

[67] R. W. Motl, M. Weikert, Y. Suh, and D. Dlugonski, "Symptom cluster and physical activity in relapsing-remitting multiple sclerosis," Research in Nursing \& Health, vol. 33, no. 5, pp. 398-412, 2010.

[68] N. F. Gordon, M. Gulanick, F. Costa et al., "Physical activity and exercise recommendations for stroke survivors: an american heart association scientific statement from the council on clinical cardiology, subcommittee on exercise, cardiac rehabilitation, and prevention; the council on cardiovascular nursing; the council on nutrition, physical activity, and metabolism; and the stroke council," Circulation, vol. 109, no. 16, pp. 2031-2041, 2004.

[69] R. W. Motl, E. M. Snook, E. McAuley, and R. C. Gliottoni, "Symptoms, self-efficacy, and physical activity among individuals with multiple sclerosis," Research in Nursing and Health, vol. 29, no. 6, pp. 597-606, 2006.

[70] R. W. Motl, P. A. Arnett, M. M. Smith, F. H. Barwick, B. Ahlstrom, and E. J. Stover, "Worsening of symptoms is associated with lower physical activity levels in individuals with multiple sclerosis," Multiple Sclerosis, vol. 14, no. 1, pp. 140-142, 2008.

[71] E. McAuley, S. M. White, L. Q. Rogers, R. W. Motl, and K. S. Courneya, "Physical activity and fatigue in breast cancer and multiple sclerosis: psychosocial mechanisms," Psychosomatic Medicine, vol. 72, no. 1, pp. 88-96, 2010.

[72] D. R. Brittain, N. C. Gyurcsik, M. McElroy, and S. A. Hillard, "General and arthritis-specific barriers to moderate physical activity in women with arthritis," Womens Health Issues, vol. 21, no. 1, pp. 57-63, 2010.

[73] B. Schoster, L. F. Callahan, A. Meier, T. Mielenz, and L. DiMartino, "The people with arthritis can exercise (PACE) program: a qualitative evaluation of participant satisfaction," Preventing Chronic Disease, vol. 2, no. 3, p. A11, 2005.
[74] C. J. Wong, D. Goodridge, D. D. Marciniuk, and D. Rennie, "Fatigue in patients with COPD participating in a pulmonary rehabilitation program," International Journal of Chronic Obstructive Pulmonary Disease, vol. 5, pp. 319-326, 2010.

[75] A. E. Tawashy, J. J. Eng, K. H. Lin, P. F. Tang, and C. Hung, "Physical activity is related to lower levels of pain, fatigue and depression in individuals with spinal-cord injury: a correlational study," Spinal Cord, vol. 47, no. 4, pp. 301-306, 2009.

[76] N. A. Allen, "Social cognitive theory in diabetes exercise research: an integrative literature review," Diabetes Educator, vol. 30, no. 5, pp. 805-819, 2004.

[77] S. Ferrier, N. Dunlop, and C. Blanchard, "The role of outcome expectations and self-efficacy in explaining physical activity behaviors of individuals with multiple sclerosis," Behavioral Medicine, vol. 36, no. 1, pp. 7-11, 2010.

[78] M. Vissers, R. van den Berg-Emons, T. Sluis, M. Bergen, H. Stam, and H. Bussmann, "Barriers to and facilitators of everyday physical activity in persons with a spinal cord injury after discharge from the rehabilitation centre," Journal of Rehabilitation Medicine, vol. 40, no. 6, pp. 461-467, 2008.

[79] N. Stroud, C. Minahan, and S. Sabapathy, "The perceived benefits and barriers to exercise participation in persons with multiple sclerosis," Disability and Rehabilitation, vol. 31, no. 26, pp. 2216-2222, 2009.

[80] L. R. Brawley, W. J. Rejeski, and A. C. King, "Promoting physical activity for older adults: the challenges for changing behavior," American Journal of Preventive Medicine, vol. 25, no. 3, supplement 2, pp. 172-183, 2003.

[81] T. J. Bartuska, "The built environment: definition and scope," in The Built Environment: A Collaborative Inquiry into Design and Planning, W. R. McClure and T. J. Bartuska, Eds., Wiley, Hoboken, NJ, USA, 2007.

[82] P. Clarke, J. A. Ailshire, M. Bader, J. D. Morenoff, and J. S. House, "Mobility disability and the urban built environment," American Journal of Epidemiology, vol. 168, no. 5, pp. 506-513, 2008.

[83] J. R. Beard, S. Blaney, M. Cerda et al., "Neighborhood characteristics and disability in older adults," Journals of Gerontology B, vol. 64, no. 2, pp. 252-257, 2009.

[84] J. H. Rimmer, B. Riley, E. Wang, A. Rauworth, and J. Jurkowski, "Physical activity participation among persons with disabilities: barriers and facilitators," American Journal of Preventive Medicine, vol. 26, no. 5, pp. 419-425, 2004.

[85] S. E. Doerksen, R. W. Motl, and E. McAuley, "Environmental correlates of physical activity in multiple sclerosis: a crosssectional study," International Journal of Behavioral Nutrition and Physical Activity, vol. 4, p. 49, 2007.

[86] D. White, A. M. Jette, D. T. Felson et al., "Are features of the neighborhood environment associated with disability in older adults?" Disability and Rehabilitation, vol. 32, no. 8, pp. 639-645, 2010.

[87] H. Liang, K. Tomey, D. Chen, N. L. Savar, J. H. Rimmer, and C. L. Braunschweig, "Objective measures of neighborhood environment and self-reported physical activity in spinal cord injured men," Archives of Physical Medicine and Rehabilitation, vol. 89, no. 8, pp. 1468-1473, 2008.

[88] G. Whiteneck, M. A. Meade, M. Dijkers, D. G. Tate, T. Bushnik, and M. B. Forchheimer, "Environmental factors and their role in participation and life satisfaction after spinal cord injury," Archives of Physical Medicine and Rehabilitation, vol. 85, no. 11, pp. 1793-1803, 2004. 
[89] J. J. Keysor, A. M. Jette, W. Coster, J. P. Bettger, and S. M. Haley, "Association of environmental factors with levels of home and community participation in an adult rehabilitation cohort," Archives of Physical Medicine and Rehabilitation, vol. 87, no. 12, pp. 1566-1575, 2006.

[90] J. F. Sallis, R. B. Cervero, W. Ascher, K. A. Henderson, M. K. Kraft, and J. Kerr, "An ecological approach to creating active living communities," Annual Review of Public Health, vol. 27, pp. 297-322, 2006.

[91] A. Shumway-Cook, A. Patla, A. Stewart, L. Ferrucci, M. A. Ciol, and J. M. Guralnik, "Environmental components of mobility disability in community-living older persons," Journal of the American Geriatrics Society, vol. 51, no. 3, pp. 393-398, 2003.

[92] M. Rantakokko, M. Manty, S. Iwarsson et al., "Fear of moving outdoors and development of outdoor walking difficulty in older people: clinical Investigations," Journal of the American Geriatrics Society, vol. 57, no. 4, pp. 634-640, 2009.

[93] G. G. Whiteneck, C. L. Harrison-Felix, D. C. Mellick, C. A. Brooks, S. B. Charlifue, and K. A. Gerhart, "Quantifying environmental factors: a measure of physical, attitudinal, service, productivity, and policy barriers," Archives of Physical Medicine and Rehabilitation, vol. 85, no. 8, pp. 1324-1335, 2004.

[94] T. R. Frieden, "A framework for public health action: the health impact pyramid," American Journal of Public Health, vol. 100, no. 4, pp. 590-595, 2010.

[95] M. Bird, K. Hill, M. Ball et al., "The long-term benefits of a multi-component exercise intervention to balance and mobility in healthy older adults: relationship between physical functioning and physical activity in the lifestyle interventions and independence for elders pilot," Archives of Gerontology and Geriatrics, vol. 58, no. 10, pp. 1918-1924, 2010.

[96] M. E. Cress, D. M. Buchner, T. Prohaska et al., "Best practices for physical activity programs and behavior counseling in older adult populations," Journal of Aging and Physical Activity, vol. 13, no. 1, pp. 61-74, 2005.

[97] V. Conn, A. Hafdahl, S. Moore, P. Nielsen, and L. Brown, "Meta-analysis of interventions to increase physical activity among cardiac subjects," International Journal of Cardiology, vol. 133, no. 3, pp. 307-320, 2009.

[98] V. Conn, A. Hafdahl, M. Minor, and P. Nielsen, "Physical activity interventions among adults with arthritis: metaanalysis of outcomes," Seminars in Arthritis and Rheumatism, vol. 37, no. 5, pp. 307-316, 2008.

[99] V. Conn, A. Hafdahl, D. Porock, R. McDaniel, and P. Nielsen, "A meta-analysis of exercise interventions among people treated for cancer," Supportive Care in Cancer, vol. 14, no. 7, pp. 699-712, 2006.

[100] T. Ruppar and V. Conn, "Interventions to promote physical activity in chronically ill adults," American Journal of Nursing, vol. 110, no. 7, pp. 30-37, 2010.

[101] T. Yan, K. H. Wilber, J. Wieckowski, and W. J. Simmons, "Results from the healthy moves for aging well program: changes of the health outcomes," Home Health Care Services Quarterly, vol. 28, no. 2-3, pp. 100-111, 2009.

[102] A. Marsh, E. Chmelo, J. Katula, S. Mihalko, and W. Jack Rejeski, "Should physical activity programs be tailored when older adults have compromised function?" Journal of Aging and Physical Activity, vol. 17, no. 3, pp. 294-306, 2009.

[103] R. W. Motl, "Physical activity and irreversible disability in multiple sclerosis," Exercise and Sport Sciences Reviews, vol. 38, no. 4, pp. 186-191, 2010.
[104] R. W. Motl, E. McAuley, S. Doerksen, L. Hu, and K. S. Morris, "Preliminary evidence that self-efficacy predicts physical activity in multiple sclerosis," International Journal of Rehabilitation Research, vol. 32, no. 3, pp. 260-263, 2009.

[105] M. A. Plow, L. Resnik, and S. M. Allen, "Exploring physical activity behaviour of persons with multiple sclerosis: a qualitative pilot study," Disability and Rehabilitation, vol. 31, no. 20, pp. 1652-1665, 2009.

[106] M. L. Finlayson and E. W. Peterson, "Falls, aging, and disability," Physical Medicine and Rehabilitation Clinics of North America, vol. 21, no. 2, pp. 357-373, 2010.

[107] C. M. Dean, C. Rissel, M. Sharkey et al., "Exercise intervention to prevent falls and enhance mobility in community dwellers after stroke: a protocol for a randomised controlled trial," BMC Neurology, vol. 9, p. 38, 2009.

[108] J. Davis, M. Robertson, M. Ashe, T. Liu-Ambrose, K. M. Khan, and C. A. Marra, "Does a home-based strength and balance programme in people aged $>$ or $=80$ years provide the best value for money to prevent falls? a systematic review of economic evaluations of falls prevention interventions," British Journal of Sports Medicine, vol. 44, no. 2, pp. 80-89, 2010.

[109] R. T. Ackermann, B. Williams, H. Q. Nguyen, E. M. Berke, M. L. Maciejewski, and J. P. LoGerfo, "Healthcare cost differences with participation in a community-based group physical activity benefit for medicare managed care health plan members," Journal of the American Geriatrics Society, vol. 56, no. 8, pp. 1459-1465, 2008.

[110] S. L. Hughes, R. B. Seymour, R. T. Campbell, P. Desai, G. Huber, and H. J. Chang, "Fit and strong!: bolstering maintenance of physical activity among older adults with lower-extremity osteoarthritis," American Journal of Health Behavior, vol. 34, no. 6, pp. 750-763, 2010.

[111] M. L. Boutaugh, "Arthritis foundation community-based physical activity programs: effectiveness and implementation issues," Arthritis Care and Research, vol. 49, no. 3, pp. 463470, 2003.

[112] M. Bruno, S. Cummins, L. Gaudiano, J. Stoos, and P. Blanpied, "Effectiveness of two arthritis foundation programs: walk with ease, and you can break the pain cycle," Clinical Interventions in Aging, vol. 1, no. 3, pp. 295-306, 2006.

[113] K. R. Lorig, D. S. Sobel, A. L. Stewart et al., "Evidence suggesting that a chronic disease self-management program can improve health status while reducing hospitalization: a randomized trial," Medical Care, vol. 37, no. 1, pp. 5-14, 1999.

[114] L. Ehrlich-Jones, T. Mallinson, H. Fischer et al., "Increasing physical activity in patients with arthritis: a tailored health promotion program," Chronic Illness, vol. 6, no. 4, pp. 272$281,2010$.

[115] G. J. Norman, M. F. Zabinski, M. A. Adams, D. E. Rosenberg, A. L. Yaroch, and A. A. Atienza, "A review of ehealth interventions for physical activity and dietary behavior change," American Journal of Preventive Medicine, vol. 33, no. 4, pp. 336-347, 2007.

[116] N. Kaufman, "Internet and information technology use in treatment of diabetes: advanced technologies and treatments for diabetes," International Journal of Clinical Practice, vol. 64, no. 166, pp. 41-46, 2010.

[117] V. Fung, K. So, E. Park et al., "The utility of a video game system in rehabilitation of burn and nonburn patients: a survey among occupational therapy and physiotherapy practitioners," Journal of Burn Care \& Research, vol. 33, no. 5, pp. 768-775, 2010. 
[118] M. A. Williams, R. L. Soiza, A. M. Jenkinson, and A. Stewart, "EXercising with computers in later life (EXCELL)—pilot and feasibility study of the acceptability of the Nintendo(R) WiiFit in community-dwelling fallers," BMC Research Notes, vol. 3, p. 238, 2010.

[119] L. Yong Joo, T. Soon Yin, D. Xu et al., "A feasibility study using interactive commercial off-the-shelf computer gaming in upper limb rehabilitation in patients after stroke," Journal of Rehabilitation Medicine, vol. 42, no. 5, pp. 437-441, 2010.

[120] B. S. Lange, P. Requejo, S. M. Flynn et al., "The potential of virtual reality and gaming to assist successful aging with disability," Physical Medicine and Rehabilitation Clinics of North America, vol. 21, no. 2, pp. 339-356, 2010.

[121] D. Rosenberg, C. A. Depp, I. V. Vahia et al., "Exergames for subsyndromal depression in older adults: a pilot study of a novel intervention," The American Journal of Geriatric Psychiatry, vol. 18, no. 3, pp. 221-226, 2010.

[122] G. W. Heath, R. C. Brownson, J. Kruger et al., "The effectiveness of urban design and land use and transport policies and practices to increase physical activity: a systematic review," Journal of Aging and Physical Activity, vol. 3, pp. S55-S76, 2006.

[123] A. L. Dannenberg, R. J. Jackson, H. Frumkin et al., "The impact of community design and land-use choices on public health: a scientific research agenda," American Journal of Public Health, vol. 93, no. 9, pp. 1500-1508, 2003.

[124] I. A. Lang, D. J. Llewellyn, K. M. Langa, R. B. Wallace, and D. Melzer, "Neighbourhood deprivation and incident mobility disability in older adults," Age and Ageing, vol. 37, no. 4, pp. 403-410, 2008.

[125] H. W. Wahl, A. Fange, F. Oswald, L. N. Gitlin, and S. Iwarsson, "The home environment and disability-related outcomes in aging individuals: what is the empirical evidence?” Gerontologist, vol. 49, no. 3, pp. 355-367, 2009.

[126] W. Kerstin, B. Gabriele, and L. Richard, "What promotes physical activity after spinal cord injury? An interview study from a patient perspective," Disability and Rehabilitation, vol. 28, no. 8, pp. 481-488, 2006.

[127] J. H. Rimmer, A. Rauworth, E. Wang, P. S. Heckerling, and B. S. Gerber, "A randomized controlled trial to increase physical activity and reduce obesity in a predominantly African American group of women with mobility disabilities and severe obesity," Preventive Medicine, vol. 48, no. 5, pp. 473-479, 2009.

[128] D. E. Crews and S. Zavotka, "Aging, disability, and frailty: implications for universal design," Journal of Physiological Anthropology, vol. 25, no. 1, pp. 113-118, 2006.

[129] U.S. Environmental Protection Agency, Building Healthy Communities for Active Aging, 2010.

[130] Global Age Friendly Cities: A Guide, World Health Organization, Geneva, Switzerland, 2007.

[131] J. Lynott, J. Haase, K. Nelson et al., Planning Complete Streets for an Aging America, AARP Public Policy Institute, Washington, DC, USA, 2009.

[132] "Evidence-based disease and disability prevention program," http://www.aoa.gov/AoARoot/AoA_Programs/HPW/Evidence_Based/index.aspx\#funding.

[133] Centers for Disease Control and Prevention Healthy Aging Network, Creating Aging-Friendly Communities, 2010.

[134] S. C. Webber, M. M. Porter, and V. H. Menec, "Mobility in older adults: a comprehensive framework," The Gerontologist, vol. 50, no. 4, pp. 443-450, 2010.
[135] M. G. Stineman and J. E. Streim, "The biopsycho-ecological paradigm: a foundational theory for medicine," $P M R$, vol. 2, no. 11, pp. 1035-1045, 2010.

[136] A. M. Jette and J. J. Keysor, "Disability models: implications for arthritis exercise and physical activity interventions," Arthritis \& Rheumatism, vol. 49, no. 1, pp. 114-120, 2003.

[137] A. K. Stuifbergen, "Building health promotion interventions for persons with chronic disabling conditions," Family and Community Health, vol. 29, supplement 1, pp. 28S-34S, 2006.

[138] U.S. Department of Health and Human Services, Multiple Chronic Conditions-A Strategic Framework: Optimum Health and Quality of Life for Individuals with Multiple Chronic Conditions, Washington, DC, USA, 2010. 


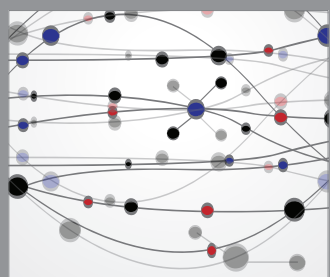

The Scientific World Journal
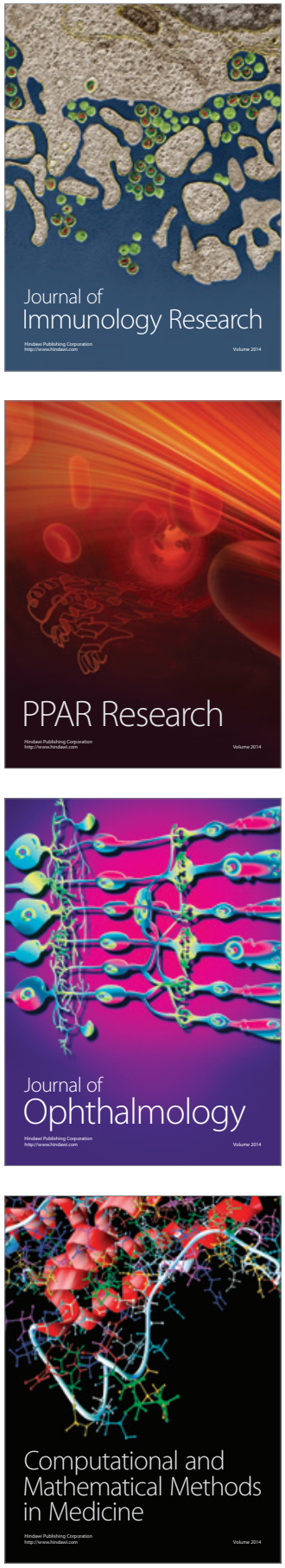

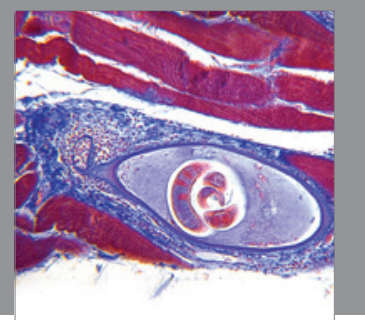

Gastroenterology

Research and Practice
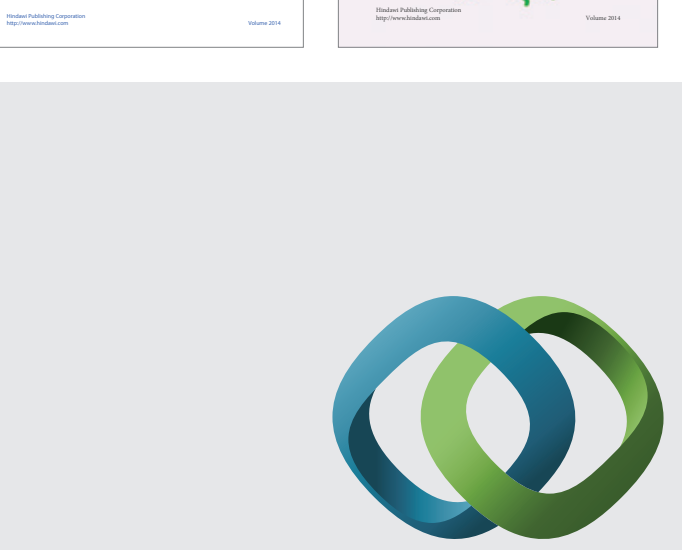

\section{Hindawi}

Submit your manuscripts at

http://www.hindawi.com
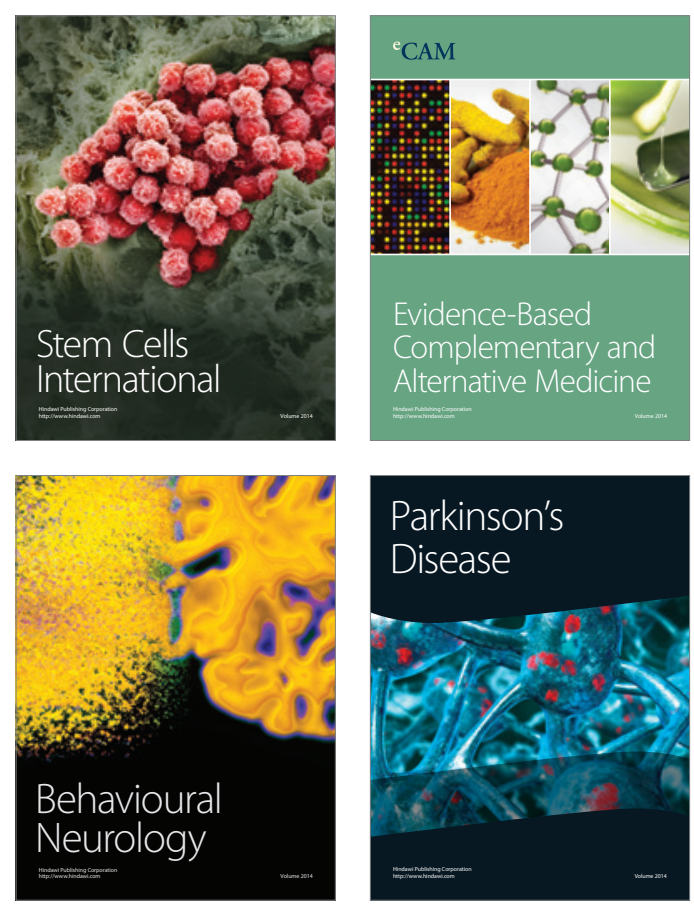

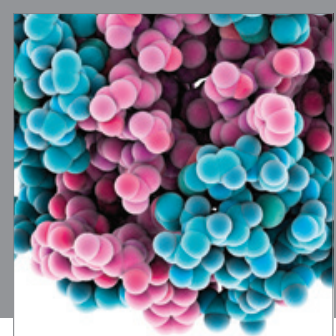

Journal of
Diabetes Research

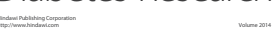

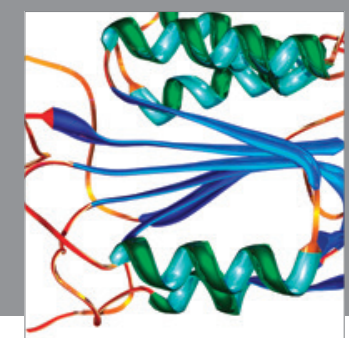

Disease Markers
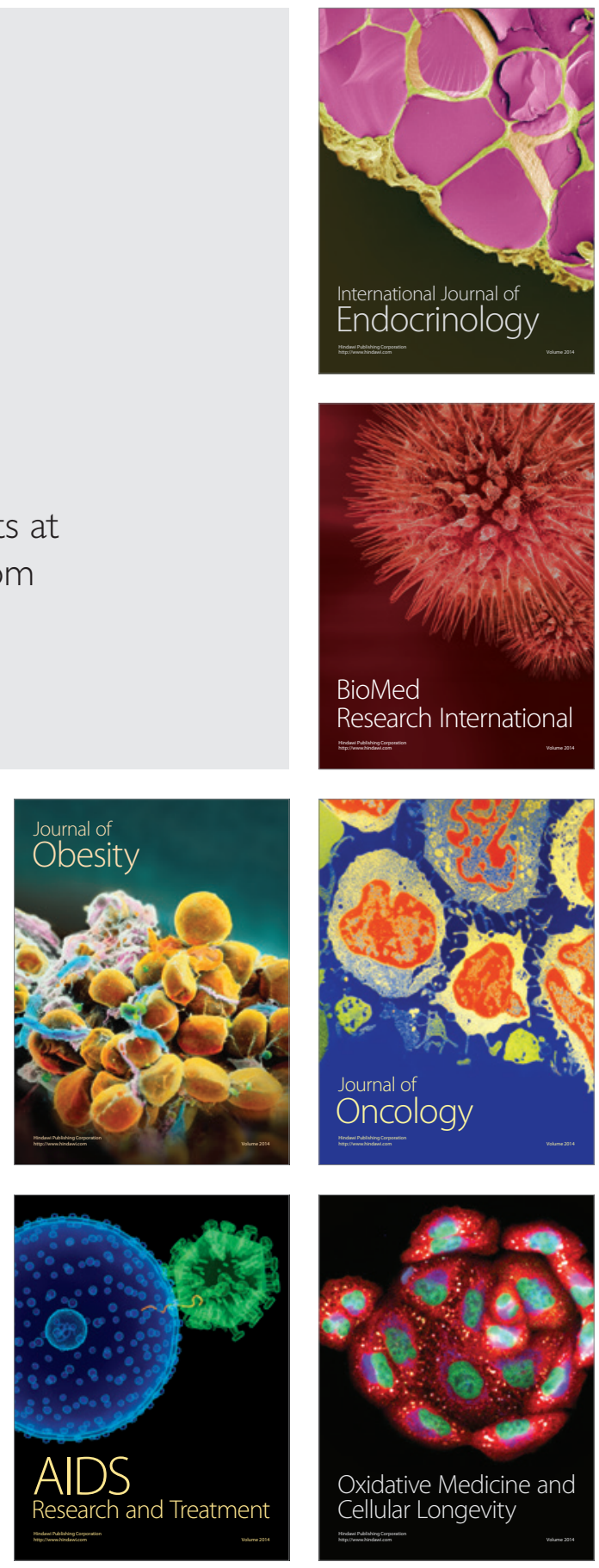